highest rate followed by county group 2. However, for gonorrhoea and P\&S syphilis, county group 2 had the highest rate for both Blacks and Whites, followed by county group 1 (see Abstract P1S5.43 table 1). In the regression analysis, gonorrhoea rates were significantly higher $(+12 \%, p<0.05)$ in counties in which black household income is below the national average and white household income is above the national average than in counties in which black and white household incomes are both below the national average. Conclusions Although other studies have demonstrated the association between income, race and STD rates, our race-income categorisation provides several new insights. Most importantly, the grouping of counties that we developed allows us to examine not only the association between STD incidence and income, but also the association between STD incidence and disparities in income. Racial disparities in income were associated with racial disparities in STDs. Specifically, when there is disparity in median household incomes for Blacks and Whites, rates of gonorrhoea and P\&S syphilis for each race are higher than when there is more equity in the median household income.

\section{P1-S5.44 STD RATES IN THE EIGHT AMERICAS: “DISPARITIES IN THE BURDEN OF SYPHILIS, GONORRHOEA, AND CHLAMYDIA ACROSS RACE AND COUNTY"}

\section{doi:10.1136/sextrans-2011-050108.222}

H Chesson, K Owusu-Edusei Jr., C Kent, S Aral. US Centers for Disease Control and Prevention Atlanta, USA

Background The purpose of this study was to examine rates of three STDs (primary and secondary syphilis, gonorrhoea, and chlamydia) in eight subpopulations (known as the eight Americas) defined by a small number of sociodemographic and geographical characteristics. Methods A list of the race-county combinations comprising each of the eight Americas was obtained from the corresponding author of the original eight Americas project, which examined disparities in mortality rates across the eight Americas. Using county-level STD surveillance data, we calculated syphilis, gonorrhoea, and chlamydia rates (new cases per 100 000) for each of the eight Americas.

Results STD rates varied substantially across the eight Americas. STD rates were generally lowest in America 1 (Asian and Pacific Islanders in selected counties) and America 2 (Northland lowincome rural white) and highest in America 6 (Black Middle America), America 7 (Southern low-income rural black), and America 8 (High-risk urban black) see Abstract P1-S5.44 Table 1. Conclusions The disparities in STD rates we observed across the eight Americas were akin to the disparities in mortality rates and life expectancy reported by the authors of the original eight Americas study. Although disparities in STDs across the eight Americas are generally similar to the well-established disparities in STDs

Abstract P1-S5.44 Table 1 STD rates (new cases per 100000) in the Eight Americas, 2008

\begin{tabular}{lccc}
\hline & $\begin{array}{l}\text { Primary and } \\
\text { secondary } \\
\text { syphilis }\end{array}$ & Gonorrhoea & Chlamydia \\
\hline 1. Asian & 1.4 & 14.5 & 100.6 \\
2. Northland low-income rural white & 0.3 & 9.2 & 125.5 \\
3. Middle America & 2.7 & 30.0 & 172.4 \\
4. Low-income whites in Appalachia & 1.1 & 23.8 & 139.4 \\
and the Mississippi Valley & & & \\
5. Western Native American & 2.9 & 80.9 & 820.7 \\
6. Black Middle America & 14.5 & 475.3 & $1,063.6$ \\
7. Southern low-income rural black & 15.3 & 482.2 & $1,109.4$ \\
8. High-risk urban black & 25.3 & 507.2 & $1,155.9$ \\
\hline
\end{tabular}

across race/ethnicity, the grouping of US race-counties into the eight Americas does offer additional insight into disparities in STDs in the USA. The high STD rates we found for Black Middle America relative to Middle America are consistent with the assertion that sexual networks and social factors are more important drivers of racial disparities in STDs than differences in sexual behaviours.

\section{P1-S5.45 ABSTRACT WITHDRAWN}

\section{Epidemiology poster session 5: Transmission dynamic: Income disparities \\ P1-S5.46 ASSESSING THE RELATIONSHIP BETWEEN SEXUALLY TRANSMITTED INFECTION RATES, ETHNIC GROUP AND SOCIO-ECONOMIC DEPRIVATION IN ENGLAND}

doi:10.1136/sextrans-2011-050108.224

E Savage, G Leong, L Peters, S Duffell, G Hughes. Health Protection Agency, London, UK

Background Disparities in the distribution of sexually transmitted infections (STIs), especially gonorrhoea, across ethnic groups in England are well recognised. Socio-economic deprivation (SED) is also a known determinant of poor health outcomes and is often more common in ethnic minorities, but it has not previously been possible to assess the relationship between ethnic group, SED and STI rates at the national level. We used data from a new national patient-level STI surveillance system to investigate the interplay between SED and ethnicity on population-level rates of STIs in England.

Methods Data on patients diagnosed with syphilis, gonorrhoea, genital herpes and genital warts from all genitourinary medicine (GUM) clinics in England in 2009 were obtained through the GUM Clinic Activity Dataset (GUMCAD). Rates of STI diagnoses by ethnic group and deprivation quintile were calculated. Deprivation was measured using the Index of Multiple Deprivation for England for each lower-level super output area of residence.

Results In England in 2009 the rate of syphilis and gonorrhoea was over five times higher (7.7/100 000 vs 1.4/100 000 and 42.8/100 000 vs $8.0 / 100000$ respectively) in the most deprived areas than in the least deprived areas but there was less difference for genital herpes (49.4/100\000 vs $26.8 / 100 \backslash 000)$ and warts (131.1/100 000 vs 79.0/ 100000 ) (see Abstract P1-S5.46 figure 1). The highest crude rates of acute STI diagnoses were among black ethnic communities although the magnitude varied by STI. The rate of gonorrhoea in black communities was over eight times higher than in white ethnic groups (171/100 000 vs 20/100 000), however, for genital warts rates in black ethnic communities were only 1.5 times higher than those in white ethnic groups (194.5/100 000 vs 130/100 000). Asians had the lowest rates for all four infections.

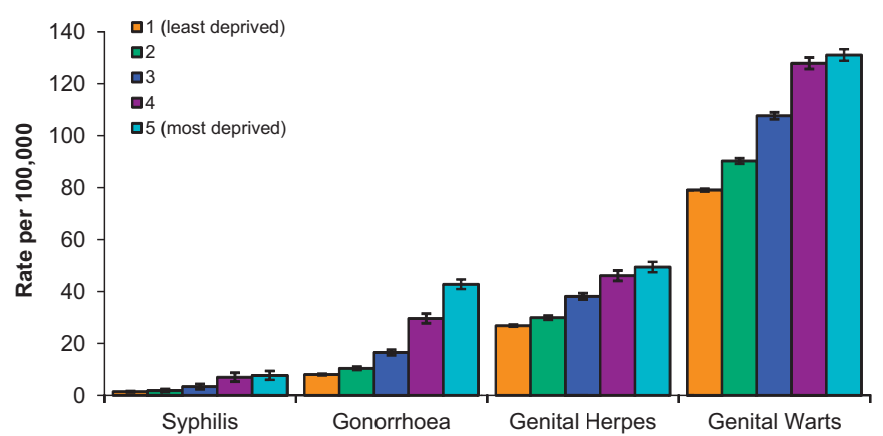

Abstract P1-S5.46 Figure 1 Rates of diagnoses of STIs by deprivation quintile using the Index of Multiple Deprivation, England, 2009. 
Conclusions Rates of STIs are strongly associated with deprivation. Presentation of STI rates by ethnic categories should be adjusted to take into account the strong interaction between ethnicity and SED. While SED is a key determinant of ill health other cultural influences on sexual behaviour may contribute to STI risk exposure among ethnic groups. The high STI rates seen among black ethnic communities are likely to be the consequence of a complex interplay of cultural, economic and behavioural factors.

\section{Epidemiology poster session 6: Preventive intervention}

\section{P1-S6.01 CONTROLLING THE HETEROSEXUAL HIV EPIDEMIC IN LOW-PREVALENCE DOMAINS}

doi:10.1136/sextrans-2011-050108.225

${ }^{1} \mathrm{C}$ Lehman, ${ }^{2} \mathrm{~A}$ Keen, ${ }^{3} \mathrm{~B}$ Kerr. ${ }^{1}$ University of Minnesota, St Paul, USA; ${ }^{2}$ London School of Hygiene and Tropical Medicine, London, UK; ${ }^{3}$ University of Washington, Seattle, USA

Background HIV/AIDS has a manifest ability to swell to epidemic proportions and debilitate entire societies. Currently, the disease remains below the level of a generalised epidemic ${ }^{1}$ in the USA and many other developed nations. Yet the number of reported HIV infections continues to expand steadily. ${ }^{2}$ The same strains of virus affect all humans, but their ecology and epidemiology are markedly different in opposite-sex vs same-sex communities. Variance terms in the transmission equations of opposite-sex communities are reduced in same-sex communities, changing the dynamics of the disease and the interventions that could successfully control it.

Methods and Results We apply mathematical disease models of minimal complexity and higher complexity equation-free network models to show how (1) purely epidemiological forces are sufficient to explain the rapid spread of the virus through male same-sex communities, independent of usual assumptions of more dangerous or careless sexual practices in those communities ${ }^{3}$, (2) the expansion tendencies of HIV can be counteracted in national testing and treatment programs aimed at breaking the spread of infection, and (3) simple behavioural changes resulting from increased awareness of infection through increased testing ${ }^{4}$ can conceivably bring the infection under control in the heterosexual community, even without universal voluntary testing. ${ }^{5}$

Conclusions Much world effort properly is being focused where the disease is rampant, as in opposite-sex communities in many African nations ${ }^{6}$ as well as male same-sex communities everywhere. ${ }^{7}$ Critical attention must be continued in these sensitive populations, but attention throughout the general population is called for as an additional pre-emptive measure. Our results illustrate how expanded efforts in low-prevalence heterosexual communities throughout the developed world could moderate the expanding infection there, arrest it before it reaches run-away levels, and conceivably cause it to decline and eventually vanish from the general population.

\footnotetext{
REFERENCES

Karon, et al. Am J Pub Health 2001;91:1060-8.

Bristol. The Lancet 2008;372:1869-70.

Boily, et al. Sexually Trans Diseases 2004; 31:100-13.

Marks, et al. J AIDS 2005;39:446-53.

Granich, et al. The Lancet 2009:373:48-57.

De Cock, et al. The Lancet 2003;362:1847-49.

Morin, et al. AIDS and Behav 2003;7:353-62.
}

\section{P1-S6.02 CONTRACEPTIVE DISCONTINUATION BY RURAL KENYAN WOMEN IN HIV DISCORDANT PARTNERSHIPS AFTER EXITING AN HIV PREVENTION TRIAL}

doi:10.1136/sextrans-2011-050108.226

${ }^{1} \mathrm{~K}$ Ngure, ${ }^{2} \mathrm{~J}$ Baeten, ${ }^{2} \mathrm{~J}$ Lingappa, ${ }^{2} \mathrm{R}$ Heffron, ${ }^{1} \mathrm{P}$ Musingila, ${ }^{2} \mathrm{E}$ Irungu, ${ }^{1} \mathrm{P}$ Mwaniki, ${ }^{1} \mathrm{~L}$ Mwaniki, ${ }^{1} \mathrm{R}$ Wamae, ${ }^{1} \mathrm{~S}$ Mburu, ${ }^{2,3} \mathrm{~N}$ Mugo. ${ }^{1}$ Kenyatta National Hospital, Nairobi, Kenya; ${ }^{2}$ University of Washington, USA; ${ }^{3}$ Kenyatta National Hospital, Kenya

Background Women in biomedical HIV prevention clinical trials are frequently counselled to use effective contraceptive methods in order to avoid pregnancy during the study and consequent withholding of study products. Moreover, research study participants often have access to medical care at research clinics that might not otherwise be as readily available in their communities. We evaluated change in contraceptive use among women after exiting from a biomedical HIV prevention clinical trial in Kenya.

Methods The Partners in Prevention HSV/HIV Transmission Study enrolled HIV serodiscordant couples at 14 sites in East Africa and Southern Africa, including a site in Thika, Kenya. Participants were offered contraception free-of-charge at the research site during the clinical trial. Unblinding visits, at which the results of the trial were conveyed to participants, were conducted after the trial results were reported. Contraceptive use data were collected at the trial exit visit and at the later study unblinding visit.

Results Among 213 women from Thika in the trial, 114 returned for the unblinding visit, of whom $80(70.2 \%)$ were HIV positive. The median time between exit and the unblinding visit was 1.11 years (ranging from 0.84 - to 2.13 years). Non-barrier contraceptive prevalence (ie, use of oral, injectable, implantable contraceptives, intrauterine devices [IUD] or surgical) dropped from $62.3 \%$ to $47.4 \%$ $(p=0.01)$ between exit and unblinding visits: from $70.0 \%$ to $53.8 \%$, $(p=0.03)$ among HIV positive women and from $44.1 \%$ to $32.4 \%$, $(p=0.31)$ among HIV negative women. However, the prevalence of IUD use among the HIV positive women increased from $3.8 \%$ to $20 \%$, $(p=0.002)$ during this period. Additionally, the proportion of women who were using condoms as their sole contraceptive method decreased, from $29 \%$ at study exit to $1.8 \%$ at the unblinding visit $(p<0.0001)$, resulting in greater numbers of women who were not using any contraceptive method.

Conclusions There was a high rate of contraceptive discontinuation, both hormonal and barrier methods, after women exited from a biomedical HIV prevention trial. Discontinuation of contraception may reflect participant fertility desires after trial procedures are completed, or may reflect loss of clinical and counselling services available during the study. Innovative strategies to support the contraceptive needs of women after exiting HIV prevention trials are urgently needed.

\section{P1-S6.03 WHY ARE SO MANY OF OUR BIOMEDICAL AND BEHAVIOURAL PREVENTION TRIALS FAILING?}

doi:10.1136/sextrans-2011-050108.227

D Celentano, C Beyrer. Johns Hopkins Bloomberg School of Public Health, Baltimroe, USA

Background With a few exceptions, most biomedical and behavioural randomised, controlled prevention trials have failed to demonstrate efficacy. The recently reported iPrEx Trial on preexposure prophylaxis, the Thai prophylactic vaccine trials and the CAPRISA 004 trial of a female-controlled microbicide demonstrated only modest protection from HIV acquisition in high-risk populations, although both attained statistical significance. Understanding why most trials fail is important to designing trials that may have greater success in the field.

Methods We conducted a desk review of all Phase III biomedical and behavioural prevention trials reported in the past 10 years, including 